\title{
Current migraine management - patient acceptability and future approaches
}

\author{
Arnaud Fumal \\ Jean Schoenen \\ Departments of Neurology \\ and Functional Neuroanatomy, \\ Headache Research Unit, University \\ of Liège, Belgium
}

\begin{abstract}
Despite its high prevalence and individual as well as societal burden, migraine remains underdiagnosed and undertreated. In recent years, the options for the management of migraine patients have greatly expanded. A number of drugs belonging to various pharmacological classes and deliverable by several routes are now available both for the acute and the preventive treatments of migraine. Nevertheless, disability and satisfaction remain low in many subjects because treatments are not accessible, not optimized, not effective, or simply not tolerated. There is thus still considerable room for better education, for more efficient therapies and for greater support from national health systems. In spite of useful internationally accepted guidelines, anti-migraine treatment has to be individually tailored to each patient taking into account the migraine subtype, the ensuing disability, the patient's previous history and present expectations, and the co-morbid disorders. In this article we will summarize the phenotypic presentations of migraine and review recommendations for acute and preventive treatment, highlighting recent advances which are relevant for clinical practice in terms of both diagnosis and management.
\end{abstract}

Keywords: migraine, disability, acute treatment, preventive treatment, management

\section{Introduction}

The Global Burden of Disease study conducted by the the World Health Organization in 2000 and reported in the World Health Report 2001 shows that mental and neurological disorders collectively account for $30.8 \%$ of all years of healthy life lost to disability and, among them, migraine for $1.4 \%$, which places it in the top 20 causes of disability worldwide (Leonardi et al 2005).

The most prevalent neurological disorder is thus migraine, with an estimated 41 million cases in Europe. The total cost of migraine in Europe (including direct costs of medical care and indirect costs due to lost productivity) is estimated at $€ 27$ billion/year (Andlin-Sobocki et al 2005). Migraine seems to entail a cost of $€ 590$ per year per patient in Western European countries (Berg and Stovner 2005). This is in line with data from the US, where calculated costs (cost basis of 2004 including inflation converted to Euros) were $€ 8$ to 23 billion/year (Clouse and Osterhaus 1994; Hu et al 1999; Osterhaus et al 1992).

Although migraine is one of the commonest reasons for patients to consult their doctor and despite its enormous impact, it is still under-recognized and under-treated (Diamond et al 2007). This has various reasons. On the one hand, there are no biological markers to confirm the diagnosis and many doctors lack knowledge, time, interest, or all three, to manage migraineurs. On the other hand, there is no cure for migraine and, although effective therapies do exist, they have only partial efficiency or are not accessible to all. As a result, a proportion of affected individuals do not seek (anymore) medical help. We hope that this article, in which we will focus on 
migraine in adulthood, will help to convince that migraineurs should certainly accept their disorder and cope with it, but not resign themselves.

\section{Epidemiology}

The most recent European and American population-based studies in adults, all using International Headache Society (IHS) criteria, have found very similar prevalence rates for migraine in adults (see Steiner et al 2003; Stovner et al 2007). A recent review of available population-based studies showed a global prevalence among adults of current migraine of $11 \%$ (Stovner et al 2007). The male:female ratio for migraine among adults varies from 1:2 to $1: 3$ and women have more migraine without aura than migraine with aura
(Zwart et al 2004; Rasmussen 2001; Jensen and Stovner 2008). In the US Lipton et al $(2001,2007)$ have found a stable 1-year prevalence of $12 \%$. Studies in general populations agree that it is most common for migraineurs to have an average attack frequency of one or two per month. In clinical samples the mean frequency of attacks is obviously higher. A large number of headache sufferers with features of migraine fail to meet all IHS criteria for migraine but do so for probable migraine (attacks and/or headache missing one of the criteria A-D needed for migraine without aura, see Table 1). The 1-year prevalence for probable migraine was $14.6 \%$ (15.9\% in women, $12.6 \%$ in men) in a recent study (Patel et al 2004).

In a meta-analysis of 2612 patients suffering from Medication Overuse Headache (MOH), migraine was the

Table I Diagnostic criteria for migraine with and without aura and for chronic migraine

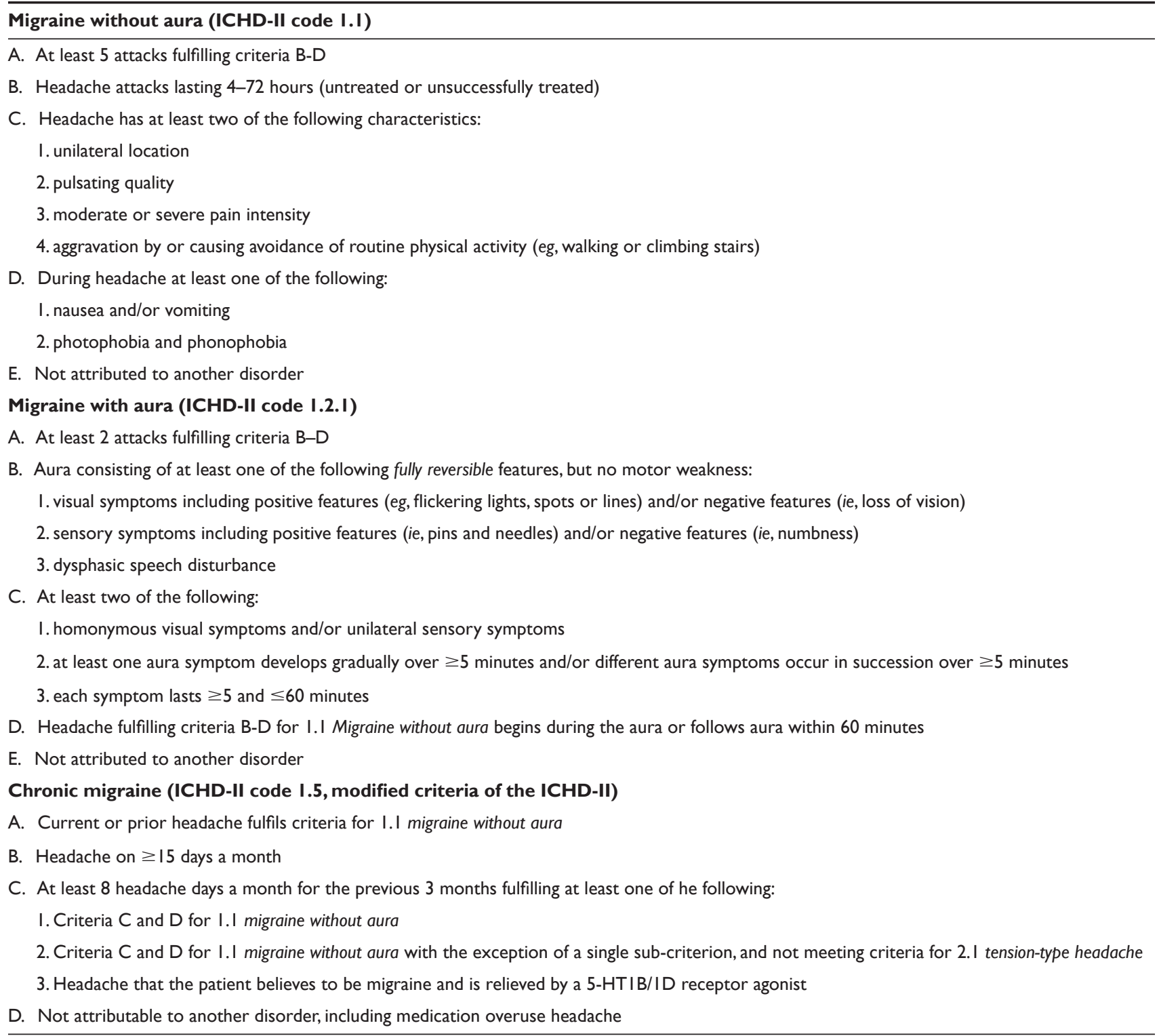


primary headache in $65 \%$ of patients, tension-type headache in $27 \%$ and all other headache combined in $8 \%$ (Diener and Dahlof 1999). About 1\%-2\% of the general population suffer from chronic daily headache associated with $\mathrm{MOH}$ (see Obermann and Katsarava 2007 for a recent review).

\section{Phenotype}

The Headache Classification with operational diagnostic criteria established by the International Headache Society (IHS) in 1988 was an important milestone for the clinical diagnosis and is accepted world-wide. Its second edition (ICHD-II) (2004) has fine tuned the classification of migraine types and settled the important issue of frequent, almost daily headache and medication overuse headache. Migraine is defined as a recurrent headache presenting in attacks which last between 4 and 72 hours. Typical features of the headache are unilateral location, pulsating quality, moderate or severe intensity, aggravation by routine physical activity and association with nausea and/or photophobia and phonophobia. The headache may be preceded in $15 \%$ to $20 \%$ of patients by an aura, so-called migraine with aura. The aura may last between 5 and 60 minutes. The most common type is visual aura, causing scotomas, teichopsia, fortification spectra, and photopsias. It can also comprise other neurological symptoms such as focal paraesthesias, speech disturbances and, in hemiplegic migraine, a unilateral motor deficit (Vincent and Hadjikhani 2007). Chronic migraine, formerly known as transformed migraine, is diagnosed when a patient has migraine on 15 or more days each month over a period of at least 3 months (recently modified ICHD-II criteria, Olesen et al 2006). Patients usually have a history of migraine attacks that gradually worsen over a period of months or years (see Table for ICHD-II diagnostic criteria). Medication-overuse headache (MOH) is defined (ICHD-II code 8.2) as a headache presenting on at least 15 days per month associated with regular overuse of one or more of the following: triptans, ergotamines, opioids or analgesics. These criteria have been revised, eliminating the headache caracteristics as diagnostic criterion and adding a new subform - $\mathrm{MOH}$ attributed to a combination of acute medications (Silberstein et al 2005; Olesen et al 2006).

The heterogeneity of the clinical phenotype of migraine is underestimated. Despite a common diagnostic denominator, some clinical features such as type of aura symptoms, pain intensity, presence of prodromes, coexistence of migraine with and without aura or associated symptoms such as vertigo, may characterize subgroups of patients bearing different underlying pathophysiological and genetic mechanisms.
Pain intensity can help to distinguish migraine without aura from tension-type headache (TTH). The TTH diagnosis, however, is mainly based on the absence of features found in other headache types such as migraine. It is thus above all a "featureless" headache characterised by nothing but pain in the head (Fumal and Schoenen 2008). Among subjects in the general population classified as TTH sufferers, a non-negligeable proportion has clinical features suggestive of migraine, like headache aggravation by routine physical exercise, pulsating quality, anorexia, photophobia, unilateral headache or nausea (Rasmussen et al 1991; Schoenen and Wang 1997). There is evidence therefore that some patients with mild migraine without aura are misdiagnosed as TTH (Fumal and Schoenen 2008).

In migraine, premonitory symptoms and trigger factors are manyfold and they may vary between patients and during the disease course. The most frequently reported premonitory symptoms are fatigue, phonophobia, and yawning (Schoonman et al 2006). Concerning trigger factors, the most common ones are stress, the perimenstrual period, and alcohol (Karli et al 2005). Overuse of acute anti-migraine drugs, in particular of combination analgesics and ergotamine, is another underestimated aggravating factor.

There is a complex interrelation between migraine and depression, both conditions being highly co-morbid (Breslau et al 2003). Episodic vertigo without other signs of basilar-type migraine might belong to the migraine phenotype (Eggers 2007).

\section{Genotype}

The common migraine phenotypes appear to be complex genetic disorders, where additive genetic effects (susceptibility genes) and environmental factors are interrelated (Stewart et al 1997). Some studies suggest different liability loci for migraine headache and aura (Haan et al 2005). Genetic abnormalities may also induce incidental subclinical dysfunctions such as for instance a reduced neuromuscular junction safety factor (Ambrosini et al 2001) or subtle cerebellar hypermetria (Sandor et al 2001a). Various gene polymorphisms were found to be more prevalent in migraineurs than in controls (Haan et al 2005). Their precise role remains to be determined; some of them may not be specific to migraine, but they could increase susceptibility to the disorder and induce endophenotypic vulnerability markers.

Heritability of migraine is a useful tool in clinical practice for helping to explain to patients that they were born with a liability for headache; by establishing that their parents also had headaches, or by pointing out that trigger 
factors do not produce headache universally, doctors can offer an explanation of migraine mechanisms, which is an expectation many patients consider as a priority when they consult (Goadsby 2006). The genetic load, ie, the "migraine susceptibility genes", can be cumulative and determines a critical attack threshold which can be modulated by external (psychosocial stress, preventive therapies ...) and internal factors (hormonal status, anxiety ...). Triggers, such as alcohol, are more likely to induce an attack when the migraine threshold is lowered, for instance in the perimenstrual period in many female migraineurs. If the threshold is reached, the cellular and molecular cascade leading to activation of the trigeminovascular system is ignited in the brain and/or brain stem. The genetic load is likely to determine the severity of the migrainous disorder, as well as some its complications like chronification by medication overuse. Some subjects will remain attack-free despite have some liability genes, while others with a less favourable genotype will continue to suffer in spite of therapeutic interventions (Sándor et al 2001b).

\section{Important issues for non-headache specialists}

Caring for a patient complaining of headaches requires above all a thorough history taking and physical examination that includes a neurological examination. To evaluate the likelihood of a secondary, symptomatic headache, the most crucial feature, besides clinical examination, is the duration of the headache history. Patients with a short history require prompt attention and may need quick complimentary investigations, while those with a longer headache history generally require time and patience rather than speed and imaging (Goadsby 2006). Red flags that should alert to the possibility of a secondary headache include pain of sudden onset, fever, marked change in pain character or timing, neck stiffness, pain associated with neurological disturbances, such as cognitive dysfunction or weakness, and pain associated with local tenderness, for example of the superficial temporal artery (Silberstein and Rosenberg 2000a). Patients with recent onset headache or with neurological signs require at the least brain imaging with computed $x$-ray tomography or magnetic resonance imaging.

\section{Pathophysiology}

The present consensus is that both neuronal and vascular components are relevant in migraine and most probably interrelated (Schoenen 1998; Sándor et al 2001b; Goadsby et al 2002). The neuronal structures involved are the cerebral cortex, the brainstem (periaqueductal gray matter, aminergic nuclei) and the peripheral as well as the central components of the trigeminovascular system. The sequence of activation and the relative role of these structures are still controversial. As migraine management is the main topic of this review article, we will not further discuss pathophysiology, which is covered in more detail elsewhere (see reviews by Moskowitz 2007; Goadsby 2007a).

\section{Management of migraine}

Besides drug and non-drug treatments, migraine management includes a seminal aspect which receives little or no consideration during medical teaching: patient information and education. This includes, as mentioned above, information about the mechanisms, potential complications and treatment options of migraine, but also education about monitoring of disease activity using a headache diary, coping strategies, ways to change life style and to avoid triggers, as well as appropriate and timely use of drug treatments and their possible adverse effects.

Traditionally, migraine treatment is subdivided into acute strategies to interrupt attacks and preventive ones to prevent attack occurrence. There is substantial room for improvement in efficacy, tolerance and safety of both acute and, even more so, preventive drug treatments. Non drug therapies with proven efficacy in migraine include blood pulse volume, skin temperature or EMG biofeedback, and acupuncture.

\section{Acute treatment}

In many patients with infrequent attacks, treatment at the time of an attack may suffice. Once the patient's preference and eventual contraindications have been taken into consideration, the following (Goadsby et al 2002) are key features for the successful use of acute anti-migraine drugs:

(i) the drug should be taken as soon as the headache component of the attack is recognized,

(ii) the dose of drug should be high enough (this is particularly important for NSAIDs, which need high dosing, eg, 600 to $1200 \mathrm{mg}$ for ibuprofen) to be fully effective in migraine,

(iii) the co-administration of anti-emetic or pro-kinetic drugs (eg, domperidone, metoclopramide) is likely to facilitate the absorption of the primary drug and thus to ameliorate speed of action and efficacy,

(iv) overuse of any acute anti-migraine drug may induce chronification and medication overuse headache; their intake should thus be restricted; we recommend no more than one day of triptans, ergotamine or combination analgesics and two days of simple analgesics or NSAIDs per week, 
(v) finally, it is important to remember, and well known to sufferers, that severity and response to treatment vary between attacks; patients may therefore require a prescription for several drugs of increasing potency to manage their attacks, allowing for a combined "stratified" (choice of drug according to severity of attack) and "step-wise within attack" (drugs of increasing potency during the attack) strategy.

\section{Non-specific anti-migraine drugs}

Drugs of first choice for mild or moderate migraine attacks are analgesics and NSAIDs. Evidence of efficacy in migraine treatment has been obtained in at least one placebo-controlled trial for acetylsalicylic acid (up to $1000 \mathrm{mg}$ ), paracetamol (1000 mg), phenazone (1000 mg), metamizol (1000 mg), ibuprofen (200 to $800 \mathrm{mg}$ ), diclofenac (50 to $100 \mathrm{mg}$ ) and tolfenamic acid (200 mg) (see Evers et al 2006 for a recent review). Several trials have shown superiority of ibuprofen (even at rather low doses of 200 to $400 \mathrm{mg}$ ) over aspirin or paracetamol in mild and moderate attacks (Nebe et al 1995; Diener et al 2004a). As ibuprofen also carries a lower risk of gastro-intestinal complications than ketoprofen, diclofenac or naproxen (Langmann et al 1994; Garcia Rodriguez et al 1994), it can be considered as the 1st choice NSAID (Figure 1). It remains to determine whether the more expensive Cox-2 inhibitors like celecoxib have an advantage over ibuprofen besides better gastric tolerance. Advising NSAIDs instead of analgesics seems also relevant in terms of prevention of medication overuse headache. Combining analgesics and/or NSAIDs to caffeine increases their efficacy (Di Monda et al 2003; Diener et al 2005; Goldstein et al 2006), but it increases also the risk of inducing medication overuse headache in susceptible patients with frequent attacks.

\section{Specific anti-migraine drugs}

The advantages of ergotamine tartrate is its low cost, long duration of action and long clinical experience The major disadvantages are the lack of evidence regarding its effective doses, its potent and sustained generalized vasoconstrictor effect, and the fact that it can induce drug overuse headache very fast and in quite low doses, especially when combined to caffeine (Evers et al 1999). There is therefore an international consensus since the avenue of triptans that there is no

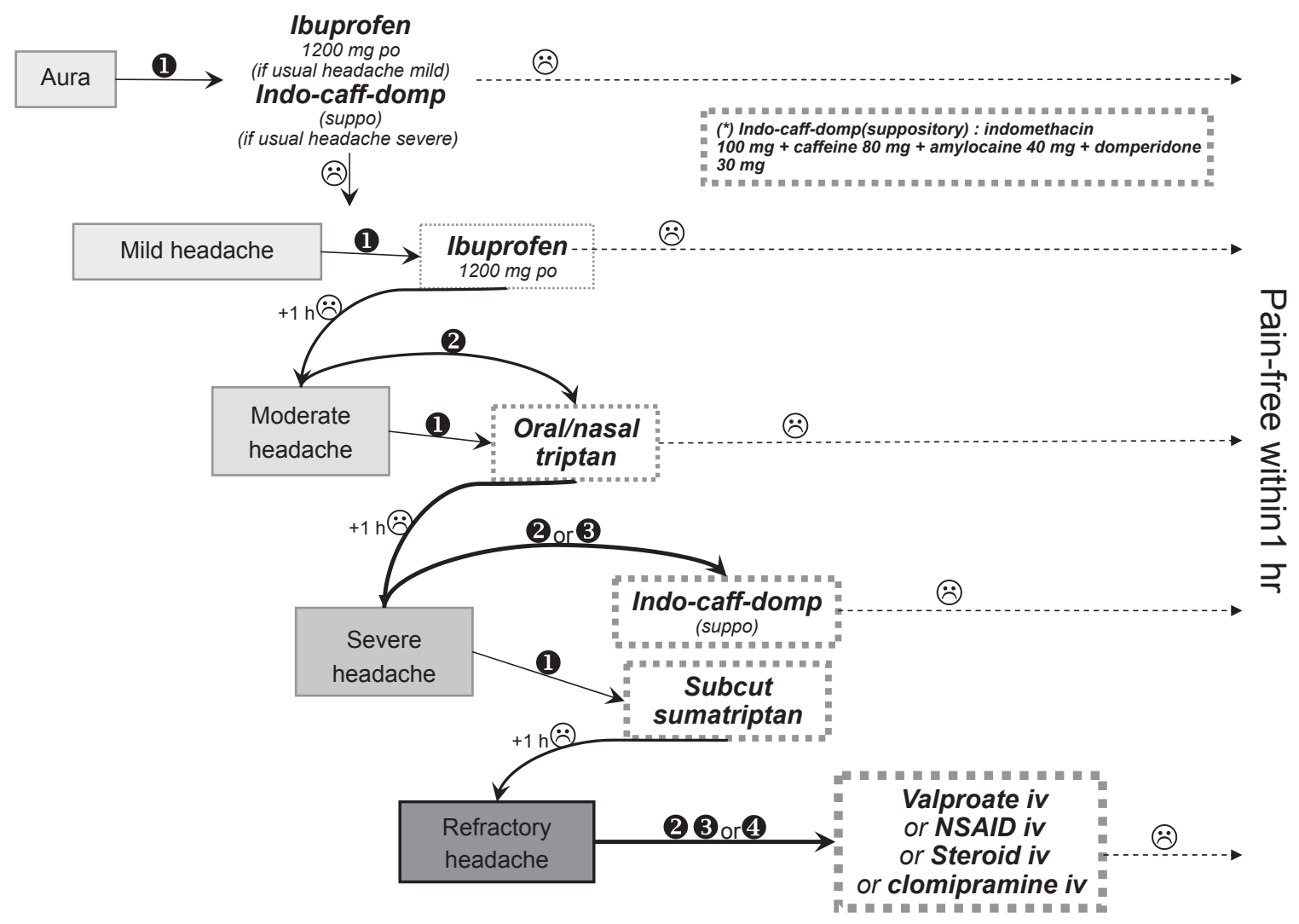

Figure I An algorithm for "stratified" and "step-wise within attack" treatment of migraine attacks, inspired from personal experience and the Belgian pharmacoeconomic situation as well as from the available literature (see reviews by Evers et al 2006; Goadsby et al 2006). 
evidence to continue to use ergot derivatives, except in patients who are already using them with excellent results and tolerance (Tfelt-Hansen et al 2000a).

Parenteral dihydroergotamine (DHE), on the contrary, is an effective treatment of migraine attacks (see meta-analysis by Colman et al 2005). It can be used as subcutaneous, intramuscular or intravenous injections. The latter may be useful in prolonged and/or refractory attacks, but must be limited to in-patients. The efficacy of intranasal DHE is inferior to that of intranasal sumatriptan (Boureau et al 2000).

During the last decade, the advent of highly effective $5-\mathrm{HT}_{1 \mathrm{~B} / \mathrm{D}}$ agonists, the triptans, has been a major breakthrough in the attack treatment. Triptans are able to act as vasoconstrictors via vascular $5-\mathrm{HT}_{1 \mathrm{~B}}$ receptors and to inhibit neurotransmitter release at the peripheral as well as at central terminal of trigeminal nociceptors via $5-\mathrm{HT}_{1 \mathrm{D} / \mathrm{B}}$ receptors (Humphrey and Goadsby 1994). The site of action relevant for their efficacy in migraine is still a matter of controversy; possibly their high efficacy rate is due to their capacity of acting at all three sites contrary to other anti-migraine drugs. Sumatriptan, the pioneer triptan, was followed by several second generation triptans (zolmi-, nara-, riza-, ele-, almo-, frovatriptan), which were developed to correct some of the shortcomings of sumatriptan.

The comparison of several randomized placebo-controlled trials performed with triptans, including the large meta-analysis by Ferrari et al (2001), indicates that the subcutaneous form of sumatriptan $(6 \mathrm{mg})$ has the best efficacy and the most rapid speed of action whatever outcome measure is considered. Differences between the oral triptans do exist for some outcome measures, but their clinical significance is questionable and in practice each patient has to find out which triptan gives him the best satisfaction.

At present, the major reason for not considering triptans as first choice treatments for migraine attacks is their high cost, and in vulnerable patients their cardiovascular side effects (Dodick et al 2004). However, stratifying care by prescribing a triptan to the most disabled patients may be cost-effective. In severely disabled migraineurs the efficacy rate of injectable sumatriptan for pain-free at 2 hours is twice/thrice that of ergot derivatives or NSAIDs taken at high oral doses (Schoenen et al 1994) and of iv acetylsalicylic acid lysinate (Diener et al 1999). The therapeutic gain tends to be clearly lower for simple analgesics or NSAIDs than for the oral triptans, when severe attacks are considered. As expected, however, triptans have not solved the patients' problems, and for the oral forms $\pm 30 \%$ of attacks do not respond and when there is a response at 2 hours disabling symptoms may persist in another $\pm 30 \%$. To improve the therapeutic score of oral triptans, they can be combined with an NSAID which increases pain-free rates and decreases recurrence rates, a benefit demonstrated in placebo-controlled trials for sumatriptan-naproxen sodium (Brandes et al 2007) and almotriptan- aceclofenac combinations (Schoenen et al 2008).

As a general rule, opiates have no place in the management of migraine attacks, because they favour medication overuse in susceptible patients and other effective drugs do exist. Exceptionally, however, they can be used with caution in some patients orally combined with analgesics or as injections for resistant disabling attacks.

The interrelation between headache response, return to normal functioning and treatment acceptability is a clinically and pharmaco-economically important consideration in the selection of an optimal migraine therapy. Davies et al (2000) studied the relationship between clinical trial end points and patients' satisfaction with acute migraine treatments: when pain-free at 2 hours post-dosing, more than $90 \%$ of patients declared they were satisfied with the treatment; when mild pain persisted at 2 hours, $60 \%$ to $80 \%$ did so and the proportion dropped to $<10 \%$ when pain remained moderate or severe. Rapid headache relief and return to normal function are the main factors correlating with treatment acceptability (Pradel et al 2006).

Figure 1 shows an algorithm for a "stratified" and "step-wise within attack" strategy for the treatment of migraine attacks, inspired from the available literature (see reviews by Evers et al 2006 and Goadsby et al 2006) as well as from personal experience and the Belgian pharmaco-economic situation.

\section{Prophylactic therapy in migraine}

Prophylactic anti-migraine treatment has to be individually tailored to each patient taking into account his disability, demands, expectations and previous history, the migraine subtype and the co-morbid disorders.

\section{Drug treatments}

Except for methysergide which was designed on basis of the "hyper-serotonin" theory of the migraine attack, the major prophylactic anti-migraine drugs were not developed specifically for migraine and their efficacy is thus based on empirical data. As a matter of fact, they belong to very different pharmacological classes and their mode of action in migraine may be remote from their principal pharmacological target, which is further underlined by the 
fact that not all agents belonging to a class have proven anti-migraine efficacy. The 4 major classes are beta-blockers (but only those devoid of intrinsic sympathicomimetic activity), anti-convulsants (but only some like valproate and topiramate), serotonin receptor blockers (mainly methysergide), $\mathrm{Ca}^{2+}$ antagonists (but only flunarizine and verapamil) and, to a lesser degree, tricyclics. In recent years, drugs with totally different pharmacological actions were found effective in migraine prophylaxis, for example, metabolic enhancers like riboflavin (Schoenen et al 1998) and co-enzyme Q10 (Sándor et al 2005), angiotensin converting enzyme (lisinopril) (Schrader et al 2001) or receptor (candesartan) inhibitors (Tronvik et al 2003), magnesium salts (Peikert et al 1996) or herbs such as petasites (butterbur) (Diener et al 2004; Lipton et al 2004) and tanacetum parthenium (feverfew) (Diener et al 2005). Evidence-based medicine criteria are difficult to apply comprehensively to preventive pharmacotherapy because large and high quality randomised controlled trials do not exist (for old drugs such as amitriptyline) or are sparse (for low profit making drugs like most neutriceuticals) and because comparative trials are rare. A major drawback of the first group of drugs, which have on average a $50 \%$ to $60 \%$ efficacy score, is their mediocre efficacy/adverse effects profile. Adverse effects are inexistent or trivial with most drugs of the second group, but their efficacy score is lower (30\% to $50 \%$ ) and onset of action slower (Schoenen et al 2004) (Figure 2).

The decision to install a prophylactic treatment has to be carefully discussed with the patient. There is no uniformly accepted criterion for the timing of a preventive treatment. According to recent guidelines proposed by a task force of the European Federation of Neurological Societies (EFNS) (Evers et al 2006), prophylactic drug treatment should be considered and discussed with the patient when at least one of the following conditions is fulfilled: (i) the quality of life, business duties, or school attendance are severely impaired; (ii) the frequency of attacks per month is two or higher; (iii) migraine attacks do not respond to acute drug treatment; and (iv) frequent, very long, or uncomfortable auras occur.

Headache diaries are useful tools both for patients and doctors to monitor the response to preventive therapy. Each drug, except neutriceuticals, should be started at a low dose, and gradually increased up to the minimal efficient dose to minimize side effects. Patients should be informed that several weeks or months of treatment may be required to reach maximum benefit and that the first drug that we try is not always the right one. According to international criteria for controlled drug trials (Tfelt-Hansen et al 2000b), migraine

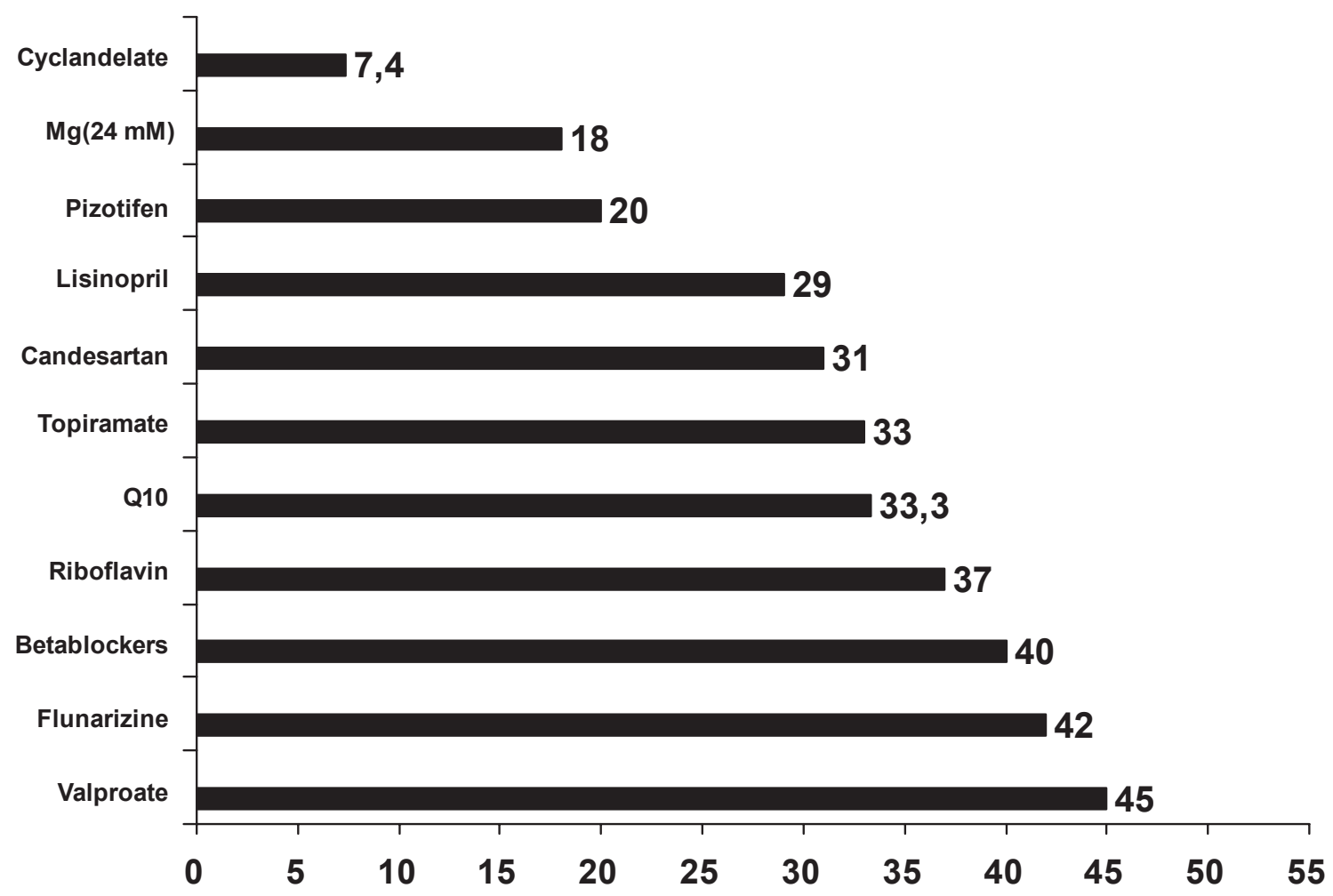

Figure 2 Therapeutic gain in migraine preventive treatment (\% of "responders", with a reduction of minimum $50 \%$ of attacks). 
prophylaxis is regarded as successful if frequency of attacks per month is decreased by at least $50 \%$ within 3 months, but in daily practice, patients' satisfaction is the gold standard. If the prescribed preventive is efficient without causing cumbersome side effects, it is continued for 6 to 8 months. After this time period, if the patient judges his amelioration as sufficient and agrees, we gradually and slowly decrease the dose over 6 to 8 weeks before stopping the treatment if there is no loss of the clinical benefit during the tapering phase. If there is a clinical aggravation during tapering, the previous (or initial) dose is reinstaured. If the treatment is not successful, dosing of the medication should be increased up to the maximum allowed or an alternative preventive treatment should be chosen (D'Amico and Lantéri-Minet 2006). The determinant of patients' compliance with an anti-migraine drug is a complex equation depending on a high efficacy/tolerance ratio which is a crucial measurable variable, but also on irrational interfering factors, such as expectation, knowledge, prejudices and concerns about the drug. Nonetheless, as shown in some studies, patients rate efficacy the most important aspect in preventive therapy and prefer treatment options with higher efficacy rates even if adverse events occur and a more frequent dosing schedule is needed (Peres et al 2007).

The EFNS task force (Evers et al 2006) proposes beta-blockers (metoprolol and propranolol), calcium channel blockers (flunarizine) and anti-convulsants (valproic acid and topiramate) as 1 st choice preventive anti-migraine treatments, while amitriptyline, bisoprolol, petasites and naproxen are drugs of second choice because they have less evidence of efficacy and/or more side effects than drugs of first choice). It classifies as drugs of third choice gabapentin, riboflavin, tanacetum parthenium, coenzyme Q10, candesartan, lisinopril, magnesium, and methysergide. One can object to this proposal that there is no evidence that the beta-blockers effective in migraine have different efficiency and that unwanted beta 2 adrenoreceptor-related bronchoconstrictor and central nervous system effects do not favour propranolol as firstchoice within this class. There is also no objective reason to prefer petasites over riboflavin or feverfew or candesartan. Amitriptyline is another problematic classification, as there is no proof for its efficacy in uncomplicated migraine from a controlled study fulfilling modern methodological requirements (Bendtsen 2003). It is nonetheless a popular drug in the USA where a Headache Consortium (Silberstein et al 2000) has even proposed it as a first choice drug, a proposal probably based on the fact that American headache experts treat at majority patients with migraine complicated by medication overuse and/or tension-type headache in whom amitriptyline is useful, rather than on its efficacy/adverse effect profile in migraine per se.

Lamotrigine is up to now the only preventive drug which has been shown effective for migraine auras (D'Andrea et al 1999; Lampl et al 2005) but not for migraine without aura (Steiner et al 1997; Gupta et al 2007).

To summarize, we prefer to separate the anti-migraine preventive drugs into 2 groups, a group of "stringent" drugs characterized by relatively high efficacy, rapid onset of action and high adverse effect incidence, and a "less stringent" group with somewhat lower efficacy, speed of action but also clearly fewer side effects (Table 2). It seems obvious to start prophylaxis in patients with relatively low attack frequency ( 2 to $4 /$ month) or with rare refractory attacks with a drug belonging to the "less stringent" group. We give preference to riboflavin because of its excellent efficacy/side effect profile and inform patients that the effect does not reach maximum before 6 to 8 weeks of treatment. Combining riboflavin to metoprolol or bisoprolol allows to keep the beta-blocker at a low, well tolerated dose, and has a pathophysiologic rationale (see above). Because of its excellent tolerance, riboflavin is also a first choice drug in children and adolescents, and, if anti-migraine prophylaxis is needed, during pregnancy (see below). In patients with more frequent attacks ( $>4 /$ month), a more rapidly acting drug is warranted such as valproate or topiramate. If these drugs fail, a trial of verapamil or methysergide or a sartan (a RCT exists only for candesartan, but in our clinical experience other sartans can be effective) is worthwhile before deciding to prescribe a combination of stringent anti-migraine drugs like topiramate and a beta-blocker. If several monotherapies are ineffective, combinations of first-line drugs should be tried before advancing to drugs of second choice, which are associated with more adverse effects or have less well-established prophylactic properties (Schürks et al 2008). There is up to now no convincing evidence that gabapentin or other new generation anti-convulsants like levetiracetam have a place in the anti-migraine armamentarium. Lamotrigine is the most efficient drug in patients who have frequent attacks of migraine with aura and no or almost no attacks without aura. If these attacks are not frequent, a trial with riboflavin is worthwhile (Figure 3). If migraine is co-morbid with hypertension, a sartan is an obvious excellent choice for preventive treatment.

\section{Botulinum toxin}

All large randomized controlled trials of pericranial injections of botulinum toxin A (BTX-A) as a preventive treatment have 
Table 2 Preventive treatments in migraine

\begin{tabular}{|c|c|}
\hline Agents and doses & Selected adverse events \\
\hline \multicolumn{2}{|l|}{ “Stringent" drugs } \\
\hline $\begin{array}{l}\beta \text {-blockers (q.d.) } \\
\text { Propranolol: } 40-160 \text { mg bisoprolol: } \\
\text { 2.5-10 mg Metoprolol: 50-200 mg }\end{array}$ & $\begin{array}{l}\text { Reduced energy, tiredness, postural hypotension, } \\
\text { bronchoconstriction, }\end{array}$ \\
\hline $\begin{array}{l}\text { Valproic acid/sodium valproate } \\
500-1000 \mathrm{mg} \text { qd } \\
\text { (sustained release) }\end{array}$ & $\begin{array}{l}\text { Sedation, nausea, weight gain, tremor, hair loss, } \\
\text { Liver toxicity, teratogenicity }\end{array}$ \\
\hline $\begin{array}{l}\text { Topiramate } \\
25-100 \mathrm{mg} \text { bid }\end{array}$ & $\begin{array}{l}\text { Paresthesias, fatigue, dysgeusia, nausea, } \\
\text { cognitive dysfunction, depression }\end{array}$ \\
\hline $\begin{array}{l}\text { Flunarizine } \\
5-10 \mathrm{mg} \text { qd }\end{array}$ & Weight gain, depression, drowsiness, parkinsonism \\
\hline $\begin{array}{l}\text { Methysergide } \\
\mathrm{I}-4 \mathrm{mg} \text { bid }\end{array}$ & $\begin{array}{l}\text { Drowsiness, leg cramps, weight gain, } \\
\text { Fibrosis (except if I month drug holiday every } 6 \text { months) }\end{array}$ \\
\hline $\begin{array}{l}\text { Amitriptyline } \\
25-75 \mathrm{mg} \text { qd }\end{array}$ & Weight gain, dry mouth, sedation, drowsiness \\
\hline \multicolumn{2}{|l|}{ “Less stringent” drugs } \\
\hline \multicolumn{2}{|l|}{$\begin{array}{l}\text { Riboflavin } \\
400 \mathrm{mg} \text { qd }\end{array}$} \\
\hline Coenzyme QI0 & \\
\hline $\begin{array}{l}\text { Lisinopril } \\
\qquad 10-20 \mathrm{mg} \text { q.d. }\end{array}$ & Cough \\
\hline $\begin{array}{l}\text { Candesartan } \\
16 \mathrm{mg} \text { qd }\end{array}$ & \\
\hline $\begin{array}{l}\text { Magnesium } \\
24-30 \mathrm{mmol} \text { qd }\end{array}$ & Abdominal cramps, diarrhea \\
\hline Petasites (butterbur) & \\
\hline Tanacetum parthenium (feverfew) & \\
\hline
\end{tabular}

failed to show superiority over placebo in episodic migraine and in tension-type headache (Silberstein et al 2005; Mathew et al 2005; Relja et al 2007; review by Delstanche and Schoenen 2006). It remains to be determined whether there is a niche for botulinum toxin A in subtypes of migraine such as chronic migraine for which two trials are ongoing.

\section{Non-drug therapies}

Several non-drug therapies have proven efficacy in migraine prophylaxis. A recent meta-analysis (total of 55 studies) showed that biofeedback significantly and substantially reduces the pain and psychological symptoms of highly chronified patients within the scope of only 11 sessions, and with a favourable long-term outcome (Nestoriuc and Martin 2007). Blood-volume-pulse feedback yielded higher effect sizes than peripheral skin temperature feedback and electromyography feedback. Another metaanalysis (Trautmann et al 2006) also provided evidence for the efficacy of psychologically based interventions (relaxation training, biofeedback and cognitive-behavioural therapy) in children and adolescent.

Acupuncture was found effective for migraine prophylaxis in several recent studies that seem methodologically appropriate in terms of modelization and statistical analysis (according to modern standards of trial design), but there still remains some controversy. In a multicenter, randomized controlled trial of 160 migraineurs (Facco et al 2007), true acupuncture had a significant and clinically relevant effect over no treatment (waiting list). In two recent studies the beneficial effect acupuncture was numerically similar to that of standard drug treatments such as beta-blockers (Streng et al 2006; Diener et al 2006). Surprisingly, however, traditional acupuncture was not superior to sham acupuncture (Linde et al 2005; Diener et al 2006), although both were superior to a waiting list arm. This suggests that needling points and other aspects considered relevant for traditional acupuncture are not relevant for treatment effect in migraine and that high levels of expectation with acupuncture may bias outcome. 


\section{Specific situations}

\section{Menstrual migraine}

The International Headache Society Classification of Headache Disorders (ICHD) includes specific definitions for pure menstrual migraine (code ICHD-II A1.1.1) and menstrually related migraine (code ICHD-II A1.1.2). Menstrual attacks are most likely to occur on the 2 days preceding menstruation and the first 3 days of bleeding (see MacGregor 2007a for a review). The acute treatment of menstrual attacks is not fundamentally different from that of non-menstrual attacks, except that one can try a short term prevention for menstrual attacks as they are predictable, and that these attacks are frequently of longer duration, needing a combination of triptans and NSAIDs.

Short term prophylaxis can be performed with NSAIDs, like ibuprofen ( $800 \mathrm{mg}$ long acting qd or $300 \mathrm{mg}$ bid) or naproxen (550 mg qd or bid) perimenstrually (Sargent et al 1985; Facchinetti et al 1989; Szekely et al 1989 and Nattero et al 1991), or with triptans (Newman et al 2001; Silberstein et al 2004) - naratriptan ( $1 \mathrm{mg}$ bid for 5 days starting 2 days prior to the expected onset of menses) and frovatriptan ( $2.5 \mathrm{mg}$ bid given for 6 days perimenstrually). Another preventive strategy is estrogen supplementation to reduce the premenstrual drop of plasma estrogen levels. The best evidence has been achieved for estradiol gel $1.5 \mathrm{mg}$ and transdermal estradiol $100 \mu \mathrm{g}$ given for 7 days perimenstrually (De Lignieres et al 1986; Smits et al 1994). There is evidence that some women responding to estrogen supplements develop a delayed attack when estrogens are discontinued. Clinical practice suggests that these women may benefit from an extension of estrogen supplementation until Day 7 of the cycle with tapering the dose over the last 2 days (MacGregor 2007a). Suppression of the menstrual cycle with continuous 3- or 6-month treatment with contraceptive agents inhibiting ovulation is another option in women who take a contraceptive pill. A variety of other treatments have been studied including magnesium and pyridoxine, but the quality of evidence for their use is poor (see Pringsheim et al 2008).

\section{Migraine during pregnancy}

In general, women can be reassured that migraine, either with or without aura, does not have any adverse effects on the outcome of pregnancy in otherwise healthy women (MacGregor 2007b). As a general rule, pregnancy from the second trimester onwards is accompanied by marked improvement or disappearance of migraine without aura, but not of migraine with aura. There are no specific clinical trials evaluating drug treatment of migraine during pregnancy, but most of the anti-migraine drugs are contraindicated. If necessary, paracetamol and metoclopramide can be used during pregnancy for the acute treatment (Evers et al 2006), and riboflavin or non-drug therapies for prevention.

\section{Migraine in children and adolescents}

For children ( $>$ age 6 years), ibuprofen $(10 \mathrm{mg} / \mathrm{kg}$ body weight) and paracetamol (15 mg/kg body weight) are effective and either can be considered for the acute treatment of migraine (Evers et al 2001). For adolescents ( $>12$ years of age), sumatriptan nasal spray is effective and should be considered as an acute treatment (Winner et al 2000). For migraine prophylaxis, riboflavin is a first choice in our experience and there is evidence of effectiveness for flunarizine 5 to $10 \mathrm{mg} /$ day and propranolol 40 to $80 \mathrm{mg} /$ day (Lewis et al 2004; Evers 1999). Other drugs have not been studied or did not show efficacy in appropriate studies.

\section{Medication-overuse headache $(\mathrm{MOH})$}

The most efficient treatment for $\mathrm{MOH}$ is abrupt drug withdrawal and immediate prescription of a preventive anti-migraine drug, but there are no studies comparing different strategies. There are thus no clear, world-wide accepted guidelines regarding modality of withdrawal or treatment of withdrawal symptoms. Oral prednisone (Krymchantowski and Barbosa 2000), tizanidine (Smith 2002), clomipramine (Lenarduzzi et al 1988), and intravenous dihydroergotamine (Raskin 1986) were found useful for withdrawal headaches, but only prednisone has been investigated in two proper randomized, placebo-controlled trials of which one showed positive results (Pageler et al 2008) while the other was negative (Bøe et al 2007).

\section{Emerging therapies for migraine Acute treatment}

As triptans are contraindicated in patients with cardio-vascular disorders, non-vasoconstricting agents are the holy grail in acute therapy research. Sserotonin 5- $\mathrm{HT}_{1 \mathrm{~F}}$ receptor agonists are currently being investigated in a phase II study in acute migraine, after a first compound LY334,370 was found effective (Goldstein et al 2001) but withdrawn because of animal toxicity problems. BIBN4096BS is a potent CGRP receptor blocker that inhibits trigeminocervical neurons and has been shown to be effective intravenously (as well or better than oral sumatriptan) (Olesen et al 2004). A novel CGRP antagonist, in an oral form, was found as effective as rizatriptan $10 \mathrm{mg}$ in terms of achieving pain freedom at $2 \mathrm{~h}$, and seemed even more effective for providing sustained freedom from pain 


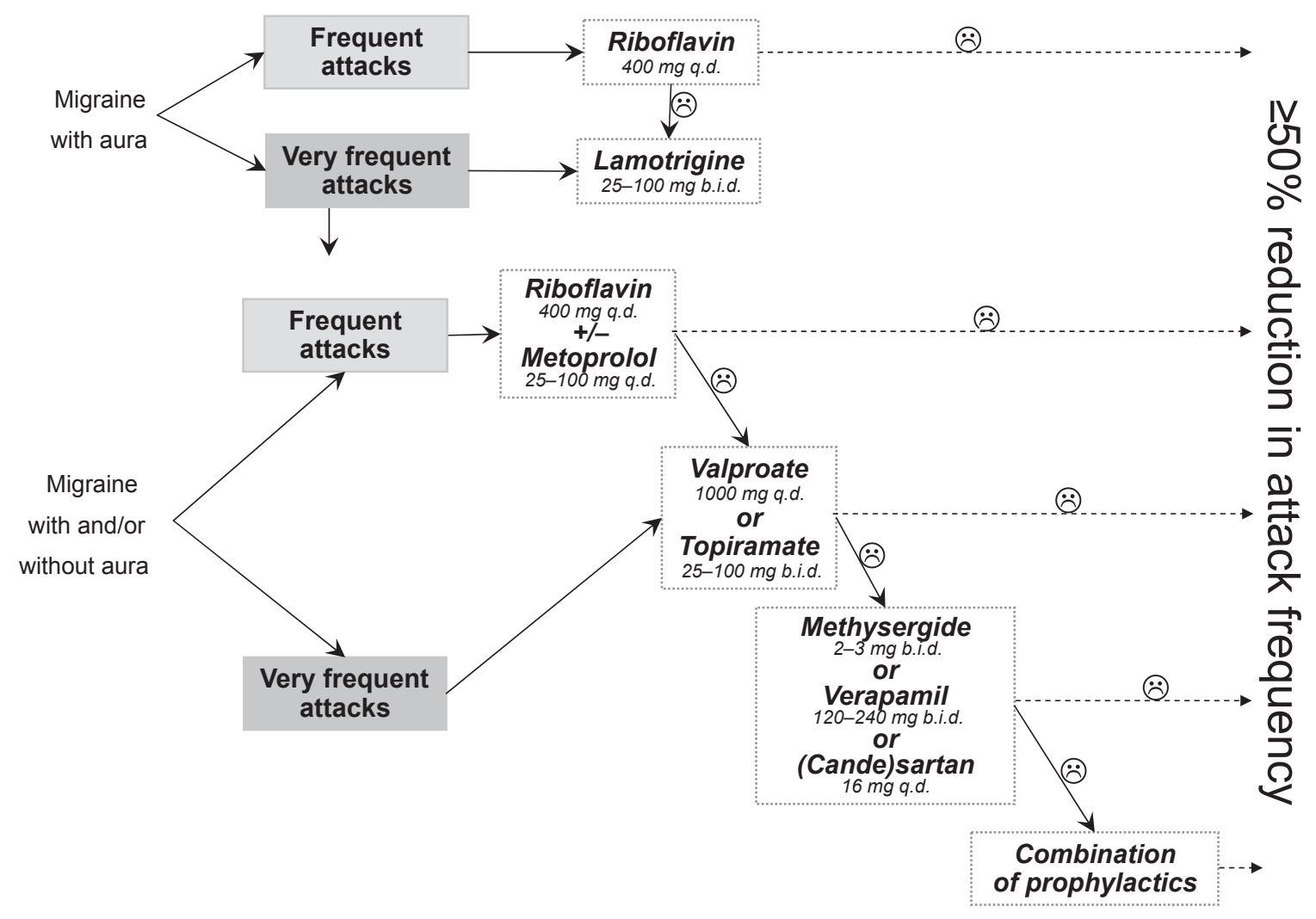

Figure 3 An algorithm for "stratified" and "step-wise" preventive anti-migraine treatment based on available data on efficacy/tolerance ratios and on personal experience.

(Ho et al 2008). In line with a role for nitric oxide (NO) in migraine pathophysiology, NO synthase (NOS) inhibition was shown to abort acute migraine in a small study (Lassen et al 1997) and more trials are in progress (see Goadsby $2007 \mathrm{~b}$ for a review). An AMPA/kainate receptor antagonist was found effective in a triple-blind, placebo-controlled trial (Sang et al 2004). A vanilloid receptor antagonist (TRPV1), SB705498, was studied in a randomized, placebo-controlled crossover study in acute migraine (NCT00269022). This study has been terminated, but as yet no results are in the public domain.

\section{Preventive treatment}

Ayata et al (2006) have found in rat that several prophylactic anti-migraine agents (topiramate, valproate, DL-propranolol, amitriptyline and methysergide) inhibit cortical spreading depression (CSD) after chronic administration. They suggested that CSD inhibition might be a common mode of action of drugs effective in migraine prevention, which is provocative and thought-provoking for several reasons (see Schoenen 2006 for discussion): (i) there is no clinical evidence that CSD occurs in migraine without aura; (ii) all compounds in Ayata et al's study were administered in very high doses compared to those used in migraine treatment; (iii) and finally, no genetic mutation able to modify the CSD threshold has been identified in the common forms of migraine. Nevertheless, cortical spreading depression (CSD) provides a possible target mechanism for the laboratory-based development of new migraine medicines. Unfortunately, a gap-junction blocker, tonabersat (SB-220453) which in animal models inhibits neurogenic inflammation, blocks propagation of CSD and inhibits trigeminal nerve ganglion stimulation-induced carotid vasodilatation, had a poor therapeutic gain of $17 \%$ in a randomized placebo-controlled phase II study (Goadsby et al 2007). Preliminary study reports have shown an effect of memantine in migraine (Cammarata and Krusz 2005; Spengos et al 2008). This is supported by a recent experimental study (Peeters et al 2007), which demonstrated that different NMDA receptor antagonists, including memantine, decrease dose-dependently cortical spreading depression (CSD).

Occipital nerve stimulation (ONS) seems a promising approach in migraine prevention (Matharu et al 2004) especially in patients who are refractory to drug treatments or do not tolerate them. Randomized trials of ONS in chronic migraine are ongoing. This technique has also proved encouraging in other primary headache disorders such as chronic cluster headache (Burns et al 2007; Magis et al 2007). Vagus nerve 
stimulation was found effective in several case reports (Sadler et al 2002; Mauskop 2005) and deserves further trials.

Patent foramen ovale is more prevalent in migraine with aura than in migraine without aura where its prevalence is comparable to that of the general population. Several retrospective and uncontrolled studies suggest that percutaneous closure of a patent foramen ovale (PFO) for cryptogenic stroke or decompression illness in divers reduces frequency of migraine attacks with, but also without aura. In one multicenter, prospective, placebo- controlled trial (MIST) the primary outcome measure, disappearance of migraine attacks, was not achieved, but there might be some improvement in attack frequency. Other controlled trials are underway and as long as their results are not known, there is no rationale for proposing PFO closure for migraine (see Schoenen et al 2006 for an extensive review and discussion).

To conclude, migraine is a common disorder of the brain which causes considerable disability. Various effective therapies are available, but there is room for improvement in acute-attack medicines, and a similar need for more efficient and better tolerable preventive approaches. A better knowledge of pathogenic mechanisms through research is mandatory before this can be achieved. Meanwhile, new emerging symptomatic treatments create new hope for patients and may contribute to decrease the burden of the disorder.

\section{Disclosures}

The have no conflicts of interest to disclose.

\section{References}

Ambrosini A, Maertens de Noordhout A, et al. 2001. Neuromuscular transmission in migraine: a single fiber EMG study in clinical subgroups. Neurology, 56:1038-43.

Andlin-Sobocki P, Jönsson B, Wittchen HU, et al. 2005. Cost of disorders of the brain in Europe. Eur J Neurol, 12(Suppl 1):1-27.

Ayata C, Jin H, Kudo C, et al. 2006. Suppression of cortical spreading depression in migraine prophylaxis. Ann Neurol, 59:652-61.

Bendtsen L. 2003. Amitriptyline in the treatment of primary headaches. Exp Rev Neurother, 3:165-73.

Berg J, Stovner LJ. 2005. Cost of migraine and other headaches in Europe. Eur J Neurol, 12(Suppl 1):59-62.

Bøe MG, Mygland A, Salvesen R. 2007. Prednisolone does not reduce withdrawal headache: a randomized, double-blind study. Neurology, 69:26-31.

Boureau F, Kappos L, Schoenen J, et al. 2000. A clinical comparison of sumatriptan nasal spray and dihydroergotamine nasal spray in the acute treatment of migraine. Int J Clin Pract, 54:281-6.

Brandes JL, Kudrow D, Stark SR, et al. 2007. Sumatriptan-naproxen for acute treatment of migraine: a randomized trial. JAMA, 297:1443-54.

Breslau N, Lipton RB, Stewart WF, et al. 2003. Comorbidity of migraine and depression: Investigating potential etiology and prognosis. Neurology, 60:1308-12.
Burns B, Watkins L, Goadsby PJ. 2007. Treatment of medically intractable cluster headache by occipital nerve stimulation: long-term follow-up of eight patients. Lancet, 369:1099-106.

Cammarata D, Krusz JC. 2005. Memantine: Novel mechanism for migraine and headache prophylaxis. Headache, 45:820.

Clouse JC, Osterhaus JT. 1994. Healthcare resource use and costs associated with migraine in a managed healthcare setting. Ann Pharmacother, 8:659-64.

Colman I, Brown MD, Innes GD, et al. 2005. Parenteral dihydroergotamine for acute migraine headache: a systematic review of the literature. Ann Emerg Med, 45:393-401.

D’Amico D, Lantéri-Minet M. 2006. Migraine preventive therapy: selection of appropriate patients and general principles of management. Expert Rev Neurother, 6:1147-57.

D'Andrea G, Granella F, Cadaldini M, et al. 1999. Effectiveness of lamotrigine in the prophylaxis of migraine with aura: an open pilot study. Cephalalgia, 19:64-6.

Davies GM, Santanello N, Lipton R. 2000. Determinants of patient satisfaction with migraine therapy. Cephalalgia, 20:554-60.

De Lignieres B, Mauvais-Javis P, Mas JML, et al. 1986. Prevention of menstrual migraine by percutaneous oestradiol. BMJ, 293:1540.

Delstanche S, Schoenen J. 2006. La toxine botulinique dans le traitement des céphalées. Neurone, 11:148-54.

Di Monda V, Nicolodi M, Aloisio A, et al. 2003. Efficacy of a fixed combination of indomethacin, prochlorperazine, and caffeine versus sumatriptan in acute treatment of multiple migraine attacks: a multicenter, randomized, crossover trial. Headache, 43:835-44.

Diamond S, Bigal ME, Silberstein S, et al. 2007. Patterns of diagnosis and acute and preventive treatment for migraine in the United States: results from the American Migraine Prevalence and Prevention study. Headache, 47:355-63.

Diener H, Pfaffenrath V, Pageler L. 2005. The fixed combination of acetylsalicylic acid, paracetamol and caffeine is more effective than single substances and dual combination for the treatment of headache: a multicentre, randomized, double-blind, single-dose, placebo-controlled parallel group study. Cephalalgia, 25:776-87.

Diener HC, Bussone G, de Liano H, et al.; EMSASI Study Group. 2004a. Placebo-controlled comparison of effervescent acetylsalicylic acid, sumatriptan and ibuprofen in the treatment of migraine attacks. Cephalalgia, 24:947-54.

Diener HC, Dahlof CG. 1999. Headache associated with chronic use of substances. In: Olesen J, Tfelt-Hansen P, Welch KMA (eds). The Headaches, 2nd ed. Lippincott, Williams and Wilkins, Philadelphia, USA. p. 871-8.

Diener HC, Kronfeld K, Boewing G, et al. GERAC Migraine Study Group. 2006. Efficacy of acupuncture for the prophylaxis of migraine: a multicentre randomised controlled clinical trial. Lancet Neurol, 5:310-6.

Diener HC, Pfaffenrath V, Schnitker J, et al. 2005. Efficacy and safety of $6.25 \mathrm{mg}$ t.i.d. feverfew CO2-extract (MIG-99) in migraine prevention-a randomized, double-blind, multicentre, placebo-controlled study. Cephalalgia, 25:1031-41.

Diener HC, Rahlfs VW, Danesch U. 2004b. The first placebo controlled trial of a special butterbur root extract for the prevention of migraine: reanalysis of efficacy criteria. Eur Neurol, 51:89-97.

Diener HC; for the ASASUMAMIG Study Group. 1999. Efficacy and safety of intravenous acetylsalicylic acid lysinate compared to subcutaneous sumatriptan and parenteral placebo in the acute treatment of migraine. A double-blind, double-dummy, randomized, multicenter, parallel group study. Cephalalgia, 19:581-8.

Dodick D, Lipton RB, Martin V, et al. Triptan Cardiovascular Safety Expert Panel. 2004. Consensus statement: cardiovascular safety profile of triptans (5-HT agonists) in the acute treatment of migraine. Headache, 44:414-25.

Eggers SD. 2007. Migraine-related vertigo: diagnosis and treatment. Curr Pain Headache Rep, 11:217-26.

Evers S, Afra J, Frese A, et al. 2006. EFNS guidelines on the drug treatment of migraine - report of an EFNS task force. Eur J Neurol, 13:560-72. 
Evers S, Gralow I, Bauer B, et al. 1999. Sumatriptan and ergotamine overuse and drug-induced headache: a clinicoepidmiologic study. Clin Neuropharmacol, 22:201-6.

Evers S, Pothmann R, Uberall M, et al. 2001. Therapie idiopathischer Kopfschmerzen im Kindesalter. Nervenheilkunde, 20:306-15.

Evers S. 1999. Drug treatment of migraine in children. A comparative review. Paediatr Drugs, 1:7-18.

Facchinetti F, Fioroni L, Sances G, et al. 1989. Naproxen sodium in the treatment of premenstrual symptoms: a placebo-controlled study. Gynecol Obstet Invest, 28:205-8.

Facco E, Liguori A, Petti F, et al. Traditional acupuncture in migraine: a controlled, randomized study. Headache. In press.

Ferrarri MD, Roon KI, Lipton RB, et al. 2001. Oral triptans (serotonin 5-HT(1B/1D) agonists) in acute migraine treatment: a meta-analysis of 53 trials. Lancet, 358:1668-75.

Fumal A, Schoenen J. 2008. Tension-type headache: current research and clinical management. Lancet Neurol, 7:70-83.

Garcia Rodriguez LA, Jick H. 1994. Risk of upper gastrintestinal bleeding and perforation associated with individual non-steroidal anti-inflammatory drugs. Lancet, 343:769-72.

Goadsby P. 2006. Recent advances in the diagnosis and management of migraine. $B M J, 332: 25-9$.

Goadsby PJ, Edvinsson L. 1993. The trigeminovascular system and migraine: studies characterizing cerebrovascular and neuropeptide changes seen in humans and cats. Ann Neurol, 33:48-56.

Goadsby PJ, Ferrari MD, Olesen J, et al. 2007. Double-blind placebo-controlled trial of tonabersat in the preventive management of migraine. Cephalalgia, 27:1195-6.

Goadsby PJ, Lipton RB, Ferrari MD. 2002. Migraine-current understanding and treatment. $N$ Engl J Med, 24:257-70.

Goadsby PJ. 2007a. Recent advances in understanding migraine mechanisms, molecules and therapeutics. Trends Mol Med, 13:39-44.

Goadsby PJ. 2007b. Emerging therapies for migraine. Nat Clin Pract Neurol, 3:610-19.

Goldstein DJ, Roon KI, Offen WW, et al. 2001. Selective seratonin $1 \mathrm{~F}(5-\mathrm{HT}(1 \mathrm{~F}))$ receptor agonist LY334370 for acute migraine: a randomised controlled trial. Lancet, 358:1230-4.

Goldstein J, Silberstein SD, Saper JR, et al. 2006. Acetaminophen, aspirin, and caffeine in combination versus ibuprofen for acute migraine: results from a multicenter, double-blind, randomized, parallel-group, single-dose, placebo-controlled study. Headache, 46:444-53.

Gupta P, Singh S, Goyal V, et al. 2007. Low-dose topiramate versus lamotrigine in migraine prophylaxis (the Lotolamp study). Headache, 47:402-12.

Haan J, Kors EE, Vanmolkot KR, et al. 2005. Migraine genetics: an update. Curr Pain Headache Rep, 9:213-20.

Ho TW, Mannix LK, Fan X, et al. On behalf of the MK-0974 Protocol 004 study group. 2008. Randomized controlled trial of an oral CGRP antagonist, MK-0974, in acute treatment of migraine. Neurology, 70:1304-12.

$\mathrm{Hu}$ XH, Markson LE, Lipton RB, et al. 1999. Burden of migraine in the United States: disability and economic costs. Arch Intern Med, 159:813-8.

Humphrey PPA, Goadsby PJ. 1994. The mode of action of sumatriptan is vascular? A debate. Cephalalgia, 14:401-10.

International Headache Society. 1988. Classification and diagnostic criteria for headache disorders, cranial neuralgia and facial pain. Cephalalgia, 8(Suppl 7):1-96.

Jensen R, Stovner LJ. 2008. Epidemiology and comorbidity of headache. Lancet Neurol, 7:354-61.

Karli N, Zarifoglu M, Calisir N, et al. 2005. Comparison of pre-headache phases and trigger factors of migraine and episodic tension-type headache: do they share similar clinical pathophysiology? Cephalalgia, 25:444-51.

Krymchantowski AV, Barbosa JS. 2000. Prednisone as initial treatment of analgesic-induced daily headache. Cephalalgia, 20:107-13.
Lampl C, Katsarava Z, Diener HC, et al. 2005. Lamotrigine reduces migraine aura and migraine attacks in patients with migraine with aura. J Neurol Neurosurg Psychiatry, 76:1730-2.

Langman MJS, Weil J, Wainwright P, et al. 1994. Risks of bleeding peptic ulcer associated with individual non-steroidal anti-inflammatory drugs. Lancet, 343:1075-8.

Lassen LH, Ashina M, Christiansen I, et al. Nitric oxide synthase inhibition in migraine. Lancet, 1997. 349:401-2.

Leão AAP. 1944. Spreading depression of activity in the cerebral cortex. J Neurophysiol, 7:359-90.

Lenarduzzi P, Schoenen J, Sianard-Gainko J. 1988. Efficacy of clomipramine during the weaning period in drug abuse headaches: a blinded study. New Trends Clin Neuropharm, II: 162.

Leonardi M, Steiner TJ, Scher AT, et al. 2005. The global burden of migraine: measuring disability in headache disorders with WHO's Classification of Functioning, Disability and Health (ICF). J Headache Pain, 6:429-40

Lewis D, Ashwal S, Hershey A, et al. American Academy of Neurology Quality Standards Subcommittee. 2004. Practice Committee of the Child Neurology Society. Practice parameter: pharmacological treatment of migraine headache in children and adolescents: report of the American Academy of Neurology Quality Standards Subcommittee and the Practice Committee of the Child Neurology Society. Neurology, 63:2215-24

Linde K, Streng A, Jürgens S, et al. 2005. Acupuncture for patients with migraine: a randomized controlled trial. JAMA, 293:2118-25.

Lipton RB, Bigal ME, Diamond M, et al. AMPP Advisory Group. 2007. Migraine prevalence, disease burden, and the need for preventive therapy. Neurology, 68:343-9.

Lipton RB, Göbel H, Einhaupl KM, et al. 2004. Petasites hybridus root (butterbur) is an effective preventive treatment for migraine. Neurology, 63:2240-4.

Lipton RB, Stewart WF, Diamond S, et al. 2001. Prevalence and burden of migraine in the United States: data from the American Migraine Study II. Headache, 41:646-57.

MacGregor A. 2007a. Menstrual migraine: a review. J Fam Plann Reprod Health Care, 33:36-47.

MacGregor A. 2007b. Migraine in pregnancy and lactation: a clinical review. J Fam Plann Reprod Health Care, 33:83-93.

Magis D, Allena M, Bolla M, et al. 2007. Occipital nerve stimulation for drug-resistant chronic cluster headache: a prospective pilot study. Lancet Neurol, 6:314-21.

Matharu MS, Bartsch T, Ward N, et al. 2004. Central neuromodulation in chronic migraine patients with suboccipital stimulators: a PET study. Brain, 127:220-30.

Mathew NT, Frishberg BM, Gawel M, et al. BOTOX CDH Study Group. 2005. Botulinum toxin type A (BOTOX) for the prophylactic treatment of chronic daily headache: a randomized, double-blind, placebo-controlled trial. Headache, 45:293-307.

Mauskop A. 2005. Vagus nerve stimulation relieves chronic refractory migraine and cluster headaches. Cephalalgia, 25:82-6.

Moskowitz MA. 2007. Genes, proteases, cortical spreading depression and migraine: impact on pathophysiology and treatment. Funct Neurol, 22:133-6.

Nattero G, Allais G, De Lorenzo C, et al. 1991. Biological and clinical effects of naproxen sodium in patients with menstrual migraine. Cephalalgia, 11(Suppl 11):201-2.

NCT00269022 [http://www.clinicaltrials.gov/ct/show/ NCT00269022?order $=1]$

Nebe J, Heier M, Diener HC. 1995. Low-dose ibuprofen in self-medication of mild to moderate headache: a comparison with acetylsalicylic acid and placebo. Cephalalgia, 15:531-5.

Nestoriuc Y, Martin A. 2007. Efficacy of biofeedback for migraine: A meta-analysis. Pain, 128:111-27.

Newman L, Mannix LK, Landy S, et al. 2001. Naratriptan as short-term prophylaxis in menstrually associated migraine: a randomised, double-blind, placebo-controlled study. Headache, 41:248-56. 
Obermann M, Katsarava Z. 2007. Management of medication-overuse headache. Exp Rev Neurother, 7:1145-55.

Olesen J, Bousser MG, Diener HC, et al. 2006. New appendix criteria open for a broader concept of chronic migraine. Cephalalgia, 26:742-6.

Olesen J, Diener HC, Husstedt IW, et al. BIBN 4096 BS Clinical Proof of Concept Study Group. 2004. Calcitonin gene-related peptide receptor antagonist BIBN $4096 \mathrm{BS}$ for the acute treatment of migraine. N Engl J Med, 350:1104-10.

Osterhaus JT, Gutterman DL, Plachetka JR. 1992. Healthcare resource and lost labour costs of migraine headache in the US. Pharmacoeconomics, 2:67-76.

Pageler L, Katsarava Z, Diener HC, et al. 2008. Prednisone vs placebo in withdrawal therapy following medication overuse headache. Cephalalgia, 28:152-6.

Patel NV, Bigal ME, Kolodner KB, et al. 2004. Prevalence and impact of migraine and probable migraine in a health plan. Neurology, 63:1432-8.

Peeters M, Gunthorpe MJ, Strijbos PJ, et al. 2007. Effects of pan - and subtype-selective N-methyl-D-aspartate receptor antagonists on cortical spreading depression in the rat: Therapeutic potential for migraine. J Pharmacol Exp Ther, 321:564-72.

Peikert A, Wilimzig C, Köhne-Volland R. 1996. Prophylaxis of migraine with oral magnesium: results from a prospective, multi-center, placebo-controlled and double-blind randomized study. Cephalalgia, 16:257-63.

Peres MF, Silberstein S, Moreira F, et al. 2007. Patients' preference for migraine preventive therapy. Headache, 47:540-5.

Pradel FG, Subedi P, Varghese AA, et al. 2006. Does earlier headache response equate to earlier return to functioning in patients suffering from migraine? Cephalalgia, 26:428-35.

Pringsheim T, Davenport WJ, Dodick D. 2008. Acute treatment and prevention of menstrually related migraine headache: Evidence-based review. Neurology, 70:1555-63.

Raskin NH. 1986. Repetitive intravenous dihydroergotamine as therapy for intractable migraine. Neurology, 36:995-7.

Rasmussen BK, Jensen R, Olesen J. 1991. A population-based analysis of the criteria of the International Headache Society. Cephalalgia, 11:129-34.

Rasmussen BK. 2001. Epidemiology of headache. Cephalalgia, 21:774-7.

Relja M, Poole AC, Schoenen J, et al. European BoNTA Headache Study Group. 2007. A multicentre, double-blind, randomized, placebo-controlled, parallel group study of multiple treatments of botulinum toxin type A (BoNTA) for the prophylaxis of episodic migraine headaches. Cephalalgia, 27:492-503.

Sadler RM, Purdy RA, Rahey S. 2002. Vagal nerve stimulation aborts migraine in patient with intractable epilepsy. Cephalalgia, 22:482-4.

Sándor PS, Ambrosini A, Agosti R, et al. 2001b. Genetics of migraine and possible links to neurophysiological abnormalities. Pain Clinical Updates, 9:1-4.

Sándor PS, Di Clemente L, Coppola G, et al. 2005. Efficacy of coenzyme Q10 in migraine prophylaxis: a randomized controlled trial. Neurology, 64:713-5.

Sándor PS, Mascia A, Seidel L, et al. 2001a. Subclinical cerebellar impairment in the common types of migraine: A 3-dimensional analysis of reaching movements. Ann Neurol, 49:668-72.

Sang CN, Ramadan NM, Wallihan RG, et al. 2004. LY293558, a novel AMPA/GluR5 antagonist, is efficacious and well tolerated in acute migraine. Cephalalgia, 24:596-602.

Sargent J, Solbach P, Damasio H, et al. 1985. A comparison of naproxen sodium to propranolol hydrochloride and a placebo control for the prophylaxis of migraine headache. Headache, 25:320-4.

Schoenen J, Bulcke J, Caekebeke J, et al. 1994. Self-treatment of acute migraine with subcutaneous sumatriptan using an auto-injector device: comparison with customary treatment in an open, longitudinal study. Cephalalgia, 14:55-63.
Schoenen J, Burette P, Materne P. 2006b. Patent foramen ovale and migraine, a fortuitus association or a causal relationship? Rev Med Liege, 61:362-8.

Schoenen J, De Klippel N, Giurgea S, et al. 2008. On behalf of the Belgian Headache Society. Almotriptan and its combination with aceclofenac for migraine attacks: a study of efficacy and the influence of auto-evaluated brush allodynia. Cephalalgia, 28:1095-105.

Schoenen J, Di Clemente L, Coppola G. 2004. Other prophylactic anti-migraine agents: riboflavin, feverfew, magnesium, Botulinum toxin, and calcium antagonists. In Olesen J, Silberstein SD, Tfelt-Hansen P (eds). Preventive Pharmacotherapy of Headache Disorders. Oxford, University Press. p. 121-33.

Schoenen J, Jacquy J, Lenaerts M. 1998. Effectiveness of high-dose riboflavin in migraine prophylaxis. A randomized controlled trial. Neurology, 50:466-70.

Schoenen J, Wang W. 1997. Tension-type Headache. In: Goadsby PJ, Silberstein SJ (eds): Headache. Boston: Butterworth-Heinemann. p. $177-200$

Schoenen J. 1998. The pathophysiology of migraine : a review based on the literature and on personal contributions. Funct Neurol, $13: 7-15$.

Schoenen J. 2006a. Future preventive therapy: are there promising drug targets? Headache Currents, 3:108-11.

Schoonman GG, Evers DJ, Terwindt GM, et al. 2006. The prevalence of premonitory symptoms in migraine: a questionnaire study in 461 patients. Cephalalgia, 26:1209-13.

Schrader H, Stovner LJ, Helde G, et al. 2001. Prophylactic treatment of migraine with angiotensin converting enzyme inhibitor (lisinopril): randomised, placebo controlled, crossover study. $B M J$, 322:19-22.

Schürks M, Diener HC, Goadsby P. 2008. Update on the prophylaxis of migraine. Curr Treat Options Neurol, 10:20-9.

Silberstein SD, Elkind AH, Schreiber C, et al. 2004. A randomized trial of frovatriptan for the intermittent prevention of menstrual migraine. Neurology, 63:261-9.

Silberstein SD, Stark SR, Lucas SM, et al. BoNTA-039 Study Group. 2005. Botulinum toxin type A for the prophylactic treatment of chronic daily headache: a randomized, double-blind, placebocontrolled trial. Mayo Clin Proc, 80:1126-37.

Silberstein SD, for the US Headache Consortium. 2000. Practice parameter: Evidence Based guidelines for migraine headache (an Evidence-based review). Neurology, 55:754-62.

Silbertsein SD, Olesen J, Bousser MG, et al. 2005. International Headache Society. The International Classification of Headache Disorders, 2nd ed - revision of criteria for 8.2 Medication-overuse headache. Cephalalgia, 25:460-5.

Smith TR. 2002. Low-dose tizanidine with nonsteroidal anti-inflammatory drugs for detoxification from analgesic rebound headache. Headache, 42:175-7.

Smits MG, van den Meer YG, Pfeil JPJM, et al. 1994. Perimenstrual migraine: effect of Estraderm TTS and the value of contingent negative variation and exteroceptive temporalis muscle suppression test. Headache, 34:103-6.

Spengos K, Theleritis C, Paparrigopoulos T. 2008. Memantine and NMDA Antagonism for Chronic Migraine: A Potentially Novel Therapeutic Approach? Headache, 48:284-6.

Steiner TJ, Findley LJ, Yuen AW. 1997. Lamotrigine versus placebo in the prophylaxis of migraine with and without aura. Cephalalgia, 17:109-12.

Steiner TJ, Scher AI, Stewart WF, et al. 2003. The prevalence and disability burden of adult migraine in England and their relationships to age, gender and ethnicity. Cephalalgia, 23:519-27.

Stewart WF, Staffa J, Lipton RB, et al. 1997. Familial risk of migraine: a population-based study. Ann Neurol, 41:166-72.

Stovner LJ, Hagen K, Jensen R, et al. 2007. The global burden of headache: a documentation of headache prevalence and disability worldwide. Cephalalgia, 27:193-210. 
Streng A, Linde K, Hoppe A, et al. 2006. Effectiveness and tolerability of acupuncture compared with metoprolol in migraine prophylaxis. Headache, 46:1492-502.

Szekely B, Meeryman S, Post G. 1989. Prophylactic effects of naproxen sodium on perimenstrual headache: a double-blind, placebo-controlled study. Cephalalgia, 9:452-3.

Tfelt-Hansen P, Block G, Dahlöf C, et al. International Headache Society Clinical Trials Subcommittee. 2000b. Guidelines for controlled trials of drugs in migraine: second edition. Cephalalgia, 20:765-86.

Tfelt-Hansen P, Saxena PR, Dahlof C, et al. 2000a. Ergotamine in the acute treatment of migraine: a review and European consensus. Brain, 123:9-18.

The International Classification of Headache Disorders. 2nd ed (ICHD-II). Cephalalgia, 2004. 24(Suppl 1):1-160.
Trautmann E, Lackschewitz H, Kröner-Herwig B. 2006. Psychological treatment of recurrent headache in children and adolescents - a meta-analysis. Cephalalgia, 26:1411-26.

Tronvik E, Stovner LJ, Helde G, et al. 2003. Prophylactic treatment of migraine with an angiotensin II receptor blocker: a randomised controlled trial. JAMA, 289:65-9.

Vincent MB, Hadjikhani N. 2007. Migraine aura and related phenomena: beyond scotoma and scintillations. Cephalalgia, 27:1368-77.

Winner P, Rothner AD, Saper J, et al. 2000. A randomized, double-blind, placebo-controlled study of sumatriptan nasal spray in the treatment of acute migraine in adolescents. Pediatrics, 106:989-97.

Zwart JA, Dyb G, Holmen TL, et al. 2004. The prevalence of migraine and tension-type headaches among adolescents in Norway. The Nord-Trøndelag Health Study (Head-HUNT-Youth), a large population-based epidemiological study. Cephalalgia, 24:373-9. 
